\title{
Area utilization of gulls in a coastal farmland landscape: habitat mosaic supports niche segregation of opportunistic species
}

\author{
Philipp Schwemmer · Stefan Garthe • \\ Roger Mundry
}

Received: 22 December 2006/Accepted: 2 January 2008/Published online: 25 January 2008

(C) Springer Science+Business Media B.V. 2008

\begin{abstract}
The intensively farmed coastal lowland landscape of Germany, adjacent to the North Sea, provides important foraging opportunities for Blackheaded, Common, Herring and Lesser Black-backed gull (Larus ridibundus, L. canus, L. argentatus and L. fuscus). We expected that spatial and temporal utilization of the landscape mosaic as well as behavioural traits and utilization of food resources would differ between these closely related species, facilitating niche segregation. We recorded habitat types and their utilization by the four species over a whole year. Furthermore, we related species abundance to several abiotic parameters. Black-headed and Common gulls were the most numerous species in the study area throughout the year. In general, the former species preferred bare fields with recently prepared soils and was often associated with tractors in the fields, whereas the latter species was most often found on pastures. Black-headed gulls seem to have a higher ability to exploit ephemeral, food sources associated with human activities whereas common gulls prefer habitats with low human activity and
\end{abstract}

P. Schwemmer $(\varangle) \cdot$ S. Garthe

Research and Technology Centre (FTZ), University of

Kiel, Hafentörn 1, 25761 Büsum, Germany

e-mail: schwemmer@ftz-west.uni-kiel.de

R. Mundry

Max Planck Institute for Evolutionary Anthropology, Deutscher Platz 6, 04103 Leipzig, Germany with naturally distributed prey. The most prominent abiotic parameter influencing gull abundance was presence of tractors. Black-headed gulls have most likely benefited from recent changes in agricultural practice, particularly the increase in cropped land, while Common gulls may have suffered from a decline in pastures. At present, utilization of the farmland habitat mosaic leads to niche segregation and supports coexistence, as two of the four gull species mainly forage in the marine environment, while there is significant habitat partitioning between the other two temporally, spatially and behaviourally.

Keywords Agriculture - Coexistence . Farming · Foraging · Habitat choice . Habitat heterogeneity $\cdot$ North Sea coast

\section{Introduction}

Gulls are opportunistic species, which can act as indicators for human induced changes in landscapes. Most species of (breeding) gulls on the German North Sea coast increased dramatically in number during the 20th century, which may be explained to an extent by favourable feeding conditions resulting from anthropogenic activities (Garthe et al. 2000). Higher numbers of gulls on terrestrial sites in the UK seem to be strongly positively correlated with the increase of intensive agriculture as well as with 
anthropogenic waste, i.e. dumps or refuse tips (e.g. Horton et al 1983; Barnett et al. 2004). Anthropogenic activities can vary considerably in their importance for different species of gulls. They may provide food sources that sustain breeding populations and may even facilitate coexistence among species (Hunt and Hunt 1973).

The coastal lowland landscape of the German North Sea coast, is affected by intensive anthropogenic (agricultural) activities. Its importance for gulls has perhaps been underestimated for a long period of time, as much more attention was spent on the internationally important, nearby Wadden Sea (e.g. Dernedde 1994). Recent investigations also have dealt with area utilization and niche segregation of gulls at sea (e.g. Kubetzki and Garthe 2003; Schwemmer and Garthe 2005), but most interestingly there are only few studies that focus on such topics in terrestrial landscapes: Vernon (1970a, 1972) points out the importance of different mainland habitat types for two gull species in the mainland of the UK during winter. However, longer periods of observation and fine-scale resolution of different habitat types are necessary to reveal the function of the landscape mosaic for gulls. Such fine-scale patterns may play subtle, but important role in terms of niche segregation. Furthermore, abiotic parameters may indirectly influence the spatio-temporal dynamics of different species in a different way by steering prey availability (e.g. Steele 1989; Honza 1993).

Closely related species within the same geographical area are expected to exhibit niche segregation through several ecological principles: (1) spatial habitat partitioning, (2) temporal differences, (3) utilization of different resources, (4) differences in behaviour (Begon et al 2006). The aim of this study is to shed light on patterns of utilization of the landscape mosaic by the four closely related gull species of the North Sea coast, Black-headed (BHG), Common (CG), Herring (HG) and Lesser Black-backed gull (LBBG) (Larus ridibundus, L. canus, L. argentatus and L. fuscus) and to elucidate niche segregation patterns with regard to these ecological principles. We compared observed and expected gull numbers on various types of farmland habitat (with different agricultural practice) and in relation to abiotic parameters and additionally conducted recordings of behaviour. The study area was typical of the regional landscape and data were recorded with high temporal resolution, thereby allowing us to investigate niche segregation patterns between closely related species in a highly dynamic agricultural landscape. We draw general conclusions on the relationship between niche segregation and the (future) development of intensive agriculture.

\section{Methods}

Study area

The study area is located on a peninsula close to the North Sea coast in the northernmost German Federal State, Schleswig-Holstein, (central coordinates: $8^{\circ} 53^{\prime} 24 \mathrm{E}$ and $54^{\circ} 09^{\prime} 36 \mathrm{~N}$; Fig. 1) and consists mainly of fields with intensive tillage intermixed with a smaller number of pastures. We conducted a total of 115 counts of all four species of gulls that used fields along a $16.8 \mathrm{~km}$ long transect route. The transect was set nearly perpendicular to the coast from a point close to the city of Büsum, the fields that the route went through $(n=208)$ encompassing a total area of $7.8 \mathrm{~km}^{2}$ (Fig. 1).

Observations took place from October 2004 to September 2005. Between 7 and 18 counts were carried out in each month (except only 4 counts in February due to heavy snow; see Fig. 2 for number of counts in each month). During each count, we recorded gull numbers and associated habitat type (for habitat availability see Table 1) as well as the behaviour of gulls. Taking into account that gull abundance as well as habitat preference would depend on season (see Atkinson et al 2002), we split the dataset into four periods: (1) winter (NovemberFebruary), (2) spring migration (March-April), (3) breeding time (May-July) and (4) autumn migration (August-October).

\section{Recording of behaviour}

We classified behaviour into three categories: (1) foraging behind tractor, (2) resting or sleeping and (3) foraging in habitats undisturbed by tractors. Individuals belonging to the third category were further subdivided into those (1) walking over the ground, (2) flying while dipping to the ground, and (3) in aerial pursuit of insects. Additionally, we recorded 
Fig. 1 Study area near the German North Sea coast. Two study areas with different scales were chosen: (1) Count transect: Polygons in the detailed map represent single fields along the count transect that were recorded 115 times in total. (2) Larger study area: bold rectangle in the detailed map indicates the area, which was surveyed once per month to determine gull abundance on different habitat types

Fig. 2 Phenology of the four gull species in the transect area in the German coastal mainland during October 2004 to September 2005. Numbers below the months depict the number of counts conducted during each month
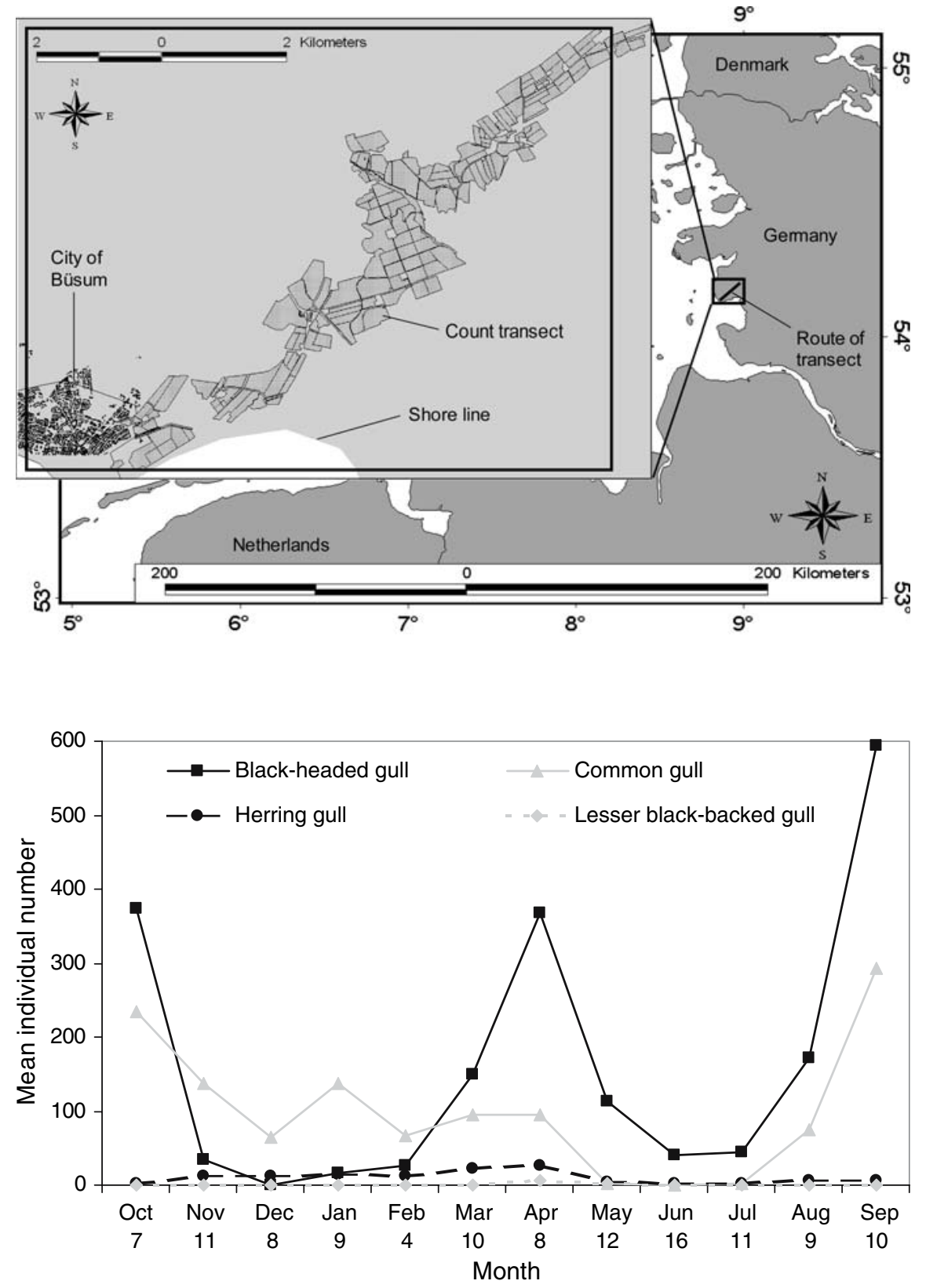

the numbers of gulls of each species following 124 tractors within a larger study area $\left(28.3 \mathrm{~km}^{2}\right.$; bold rectangle in the detailed map in Fig. 1) throughout the year. Behaviour of gulls associated with tractors was classified as (1) foraging within flock, (2) foraging outside of the flock, or (3) resting. We also computed the proportions of gulls that were associated with tractors out of the total number of gulls recorded during the 115 transect counts.

\section{Habitat preference}

Using detailed maps in a Geographic Information System (software: Arc View 3.2) that provided information on the area of each field, we calculated the total availability $\left(\mathrm{km}^{2}\right)$ of each habitat type. The total area of each habitat type varied over the course of the year due to farming activity, and so habitat availability was recorded whenever changes took 
Table 1 Mean habitat availability $\left(\mathrm{km}^{2}\right)$, proportion of the total and $\mathrm{n}$ number of fields with the respective habitat in the transect area $\left(7.8 \mathrm{~km}^{2}\right)$ during the four seasons

\begin{tabular}{|c|c|c|c|c|c|c|c|c|c|}
\hline \multirow[t]{2}{*}{ Habitat type } & \multirow{2}{*}{$\begin{array}{l}\text { Habitat } \\
\text { class }\end{array}$} & \multicolumn{2}{|l|}{ Winter } & \multicolumn{2}{|l|}{ Spring migration } & \multicolumn{2}{|l|}{ Breeding } & \multicolumn{2}{|l|}{ Autumn migration } \\
\hline & & $\begin{array}{l}\text { Availability }\left(\mathrm{km}^{2}\right) \\
\text { and proportion }\end{array}$ & $n$ & $\begin{array}{l}\text { Availability }\left(\mathrm{km}^{2}\right) \\
\text { and proportion }\end{array}$ & $n$ & $\begin{array}{l}\text { Availability }\left(\mathrm{km}^{2}\right) \\
\text { and proportion }\end{array}$ & $n$ & $\begin{array}{l}\text { Availability }\left(\mathrm{km}^{2}\right) \\
\text { and proportion }\end{array}$ & $n$ \\
\hline Drilled & 1 & $1.74(22.2 \%)$ & 31 & $1.78(22.7 \%)$ & 36 & $0.35(4.5 \%)$ & 9 & $1.78(22.7 \%)$ & 35 \\
\hline Ploughed & 1 & $0.07(0.8 \%)$ & 1 & $0.05(0.6 \%)$ & 2 & $0(-)$ & 0 & $0.36(4.6 \%)$ & 5 \\
\hline Harvested crops & 1 & $0.22(2.9 \%)$ & 4 & $0(-)$ & 0 & $0(-)$ & 0 & $0.10(1.3 \%)$ & 2 \\
\hline Vegetables & 2 & $0.31(3.9 \%)$ & 9 & $0.04(0.6 \%)$ & 1 & $1.08(13.8 \%)$ & 24 & $0.86(11.0 \%)$ & 20 \\
\hline Colza & 2 & $0.87(11.1 \%)$ & 15 & $0.96(12.2 \%)$ & 16 & $0.96(12.2 \%)$ & 15 & $0.35(4.5 \%)$ & 7 \\
\hline Stubble & 2 & $0.26(3.3 \%)$ & 7 & $0.07(0.9 \%)$ & 2 & $0(-)$ & 0 & $1.03(13.2 \%)$ & 19 \\
\hline Winter wheat & 2 & $2.19(28.0 \%)$ & 45 & $3.16(40.2 \%)$ & 63 & $3.56(45.4 \%)$ & 69 & $1.45(18.5 \%)$ & 29 \\
\hline Fallow & 3 & $0.15(1.9 \%)$ & 5 & $0.16(2.1 \%)$ & 6 & $0.27(3.4 \%)$ & 9 & $0.27(3.4 \%)$ & 9 \\
\hline Pasture & 3 & $2.03(25.9 \%)$ & 91 & $1.62(20.7 \%)$ & 82 & $1.62(20.7 \%)$ & 82 & $1.62(20.7 \%)$ & 82 \\
\hline
\end{tabular}

Habitats were classified in three categories according to agricultural practice

place (Table 1). Habitats were classified as: (1) "bare fields" = fields on which the soil has recently been prepared, (2) "fields with crops" = fields where no recent soil preparation took place, (3) "pastures and fallows" = fields with no soil preparation or cultivation (see Table 1 for detailed habitat classification).

In order to analyse habitat preference and to avoid statistical bias resulting from differences in gull numbers among the four species and habitat availability we computed a habitat preference score (HP), separately for each day of observation $(d)$, each of the three habitat classes $(h)$ and each species $(s)$. First, expected values (EXP) of gull numbers of each species within each habitat class and day were calculated by multiplying the available area of each habitat class $\left(A_{\mathrm{h}}\right)$ by the total number of each species of gulls $\left(n_{\mathrm{s}}\right)$ observed during that day and subsequently dividing by the total area $(A)$ available:

$\operatorname{EXP}_{d h s}=\frac{\left(A_{\mathrm{h}} * n_{\mathrm{s}}\right)}{A}$

Subsequently, we derived the habitat preference score $\left(\mathrm{HP}_{d h s}\right)$ by subtracting the observed numbers of each species recorded within each habitat class on a particular day $\left(\mathrm{OBS}_{d h s}\right)$ from corresponding expected values and dividing this difference by the expected values:

$\mathrm{HP}_{d h s}=\frac{\left(\mathrm{OBS}_{d h s}-\mathrm{EXP}_{d h s}\right)}{\mathrm{EXP}_{d h s}}$

This would lead to a preference score of -1 if no gulls of the species $(s)$ had been seen on the observation day in question and in the respective habitat class, to a score of 0 if the observed gull numbers exactly matched the expected values, while a positive score would indicate a preference for the respective habitat class. We added 2 to all preference scores to allow logarithmic scaling on plots and computed medians as well as the 5 and $95 \%$ percentiles. The score served to detect differences of preferences of habitat classes within and between species: (1) We tested separately for each species and season whether certain habitat classes were used more than others. (2) To compare the four gull species we conducted tests separately for each habitat class and season. We used Friedman tests to detect general significant preferences of habitat classes within species and seasons as well as species differences within habitat classes and seasons. In case of a significant result of a Friedman-test, Wilcoxontests were applied as post-hoc tests. For these analyses observation days served as sampling units. If a species was not observed at a particular day or never observed within a certain habitat class, corresponding data were excluded from the data set. Tests were only conducted if after exclusion at least six observation days remained. Wilcoxon rather than Friedman tests were applied if only two species or habitat classes remained in the data set after exclusion.

Since the same two null-hypotheses (no preferences for certain habitat classes within species and seasons as well as no species differences within habitat classes and seasons, respectively) were both tested several times (i.e. for different seasons, species 
and habitat classes), an $\alpha$-level adjustment was necessary in order to avoid reporting spurious significances. This was achieved using Fisher's Omnibus test. This procedure combines a number of $P$-values into a single $\chi^{2}$-distributed variable with its degrees of freedom equalling twice the number of $P$-values (Haccou and Meelis 1994).

\section{Densities on different habitat types}

In order to obtain information on the relative abundance of the four gull species in each agricultural habitat type we recorded gull numbers within the larger study area once per month. Densities were computed by dividing individual numbers of each species associated with each habitat type by the total area available of each habitat type. Finally, we calculated mean densities for each season.

\section{Abiotic factors}

We related total gull abundance to the following abiotic parameters: (1) wetness of the soil (wet or dry; conditions were classified as wet during/after rain or heavy dew; moisture of the soil was not measured), (2) presence/absence of tractors (present or absent), (3) wind force (Beaufort) and (4) time of day (minutes before or after noon in UTC), (5) stage of the tide (minutes after high tide). Time of day and tidal stage were initially assumed to influence gull numbers also with their square values, but since a visual inspection of the data did not yield any hints for such a relation, linear relations were considered appropriate. For statistical analysis the first two parameters were considered as class factors while the other three were treated as covariates. We tested the influence of each factor separately for both levels of the other factor using Mann-Whitney $U$-tests. The relation between total gull numbers and each of the covariates was tested using Spearman's rank correlation applied separately to each combination of the two factors. Again, we used Fisher's Omnibus test to account for multiple testing. In addition, to investigate whether correlation coefficients revealed a consistent effect across different seasons, levels of factors (e.g. tractor presence), etc., we used a one-sample $t$-test of the correlation coefficients (expected value: 0). Tests were only carried out if the sample size was sufficiently large to principally enable a significant result (Spearman's rank-correlation: $n \geq 5$; MannWhitney $U$-test: $N_{1}=N_{2} \geq 4$ or $N_{1} \geq 5, N_{2} \geq 3$ ). As a consequence, some combinations of species, season and abiotic parameter were not tested.

We carried out most statistical standard procedures using SPSS 12.0.1, whereas Spearmen's rank correlation was applied using self-written software. For non-parametric tests of small samples we used exact tests (Siegel and Castellan 1988; Mundry and Fischer 1998). Non-parametric tests of larger samples with larger proportions of tied observations were not tested using the standard approximation with correction for ties but using a permutation procedure (e.g. Manly 1997; Monte-Carlo significance, SPSS 12.0.1). Where not stated otherwise, 10,000 permutations were conducted. All indicated $P$-values are two-tailed.

\section{Results}

Abundance and phenology

Overall numbers of gulls in the coastal mainland differed among the four species: BHG showed the highest numbers and were encountered during most counts throughout the year, followed by CG, whereas HG and particularly LBBG occurred in much lower numbers (Fig. 2; Table 2). BHG and CG both showed clear peaks in numbers during autumn migration, while during spring migration BHG also showed a second peak (Fig. 2; Table 2). CG was the most abundant species during winter. All species exhibited lowest numbers during the breeding period. BHGs were present in more than $90 \%$ of all counts during breeding, but mainly in small numbers (Table 2). As numbers of LBBGs were very small and this species did not play an ecological important role in the study area, this species was excluded from the following analyses.

\section{Habitat preference}

Over all seasons, there were general significant differences in the use of the three habitat classes, both between and within species (Fisher's Omnibus tests: $\chi^{2}=46 ; \quad$ df $=22 ; \quad P<0.005 ; \quad \chi^{2}=144.1$; 
Table 2 Proportion of transect counts $(n=115)$ with sightings of at least one individual per corresponding species and maximum number (in brackets) for each season

\begin{tabular}{lllllc}
\hline & BHG & CG & HG & LBBG & $n$ counts \\
\hline Winter & $44 \%(180)$ & $84 \%(527)$ & $81 \%(53)$ & $0 \%(0)$ & 32 \\
Spring migration & $78 \%(798)$ & $78 \%(481)$ & $56 \%(105)$ & $28 \%(16)$ & 18 \\
Breeding time & $92 \%(433)$ & $26 \%(12)$ & $36 \%(23)$ & $21 \%(9)$ & 39 \\
Autumn migration & $96 \%(1,311)$ & $89 \%(1,180)$ & $50 \%(28)$ & $12 \%(1)$ & 26 \\
\hline
\end{tabular}

BHG, black-headed gull; CG, common gull; HG, herring gull; LBBG, lesser black-backed gull

df $=26 ; \quad P<0.001, \quad$ respectively; $\quad$ Fig. 3a-d). Throughout the year BHG exhibited the strongest preference for bare fields, whereas CG (except during autumn migration) and HG (except during autumn migration and breeding) showed the strongest preferences for pastures, fallows and fields with crops (see Fig. 3a-d for significant species' habitat preferences). Winter was the only season when habitat
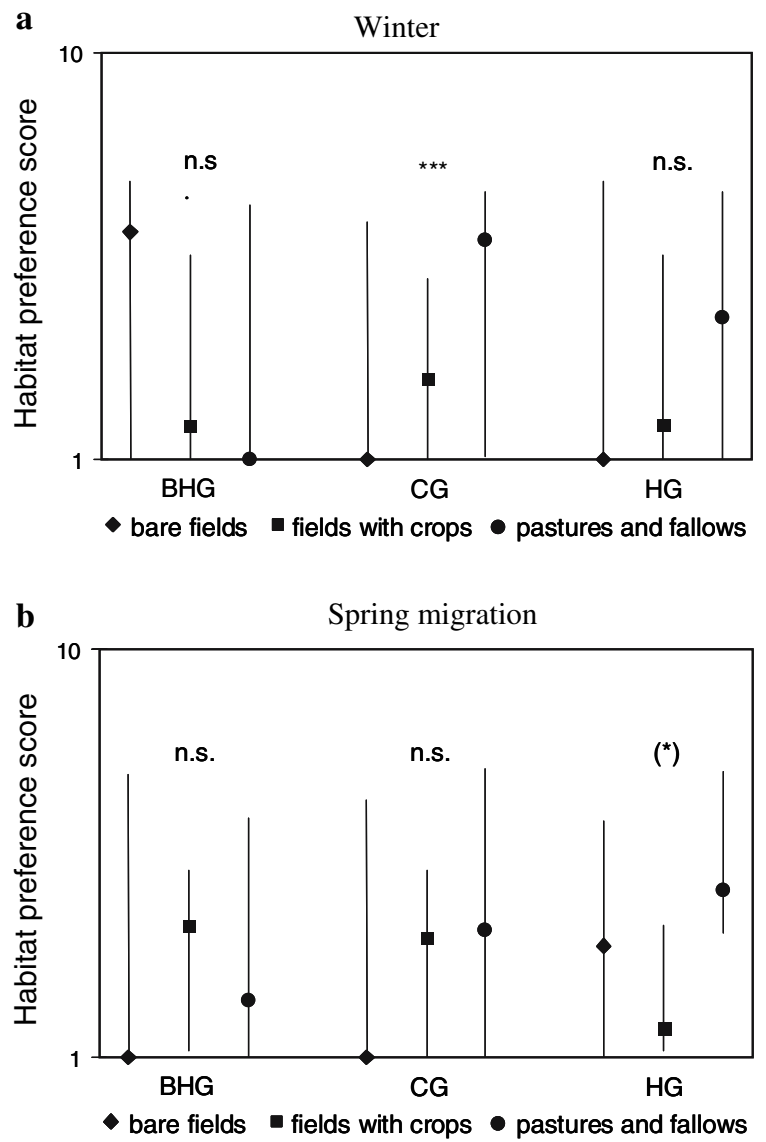

Fig. 3 Preference for different habitat classes during (a) winter, (b) spring migration, (c) breeding, (d) autumn migration. Asterisks refer to tests of differences among the preferences significantly differed between species (Friedman-tests; bare fields: $\chi^{2}=6.57$; df $=2$; $P<0.05$; pastures and follows: $\chi^{2}=13.17$; $\mathrm{df}=2$; $P<0.005$; fields with crops: $\chi^{2}=5.76$; $\mathrm{df}=2$; n.s.; Fig. 3a): BHGs used bare fields significantly more than CGs (Wilcoxon test: $T^{+}=75 ; \quad N=10$; $P<0.005)$, while the latter showed a significantly higher occurrence on pastures and fallows (Wilcoxon

c

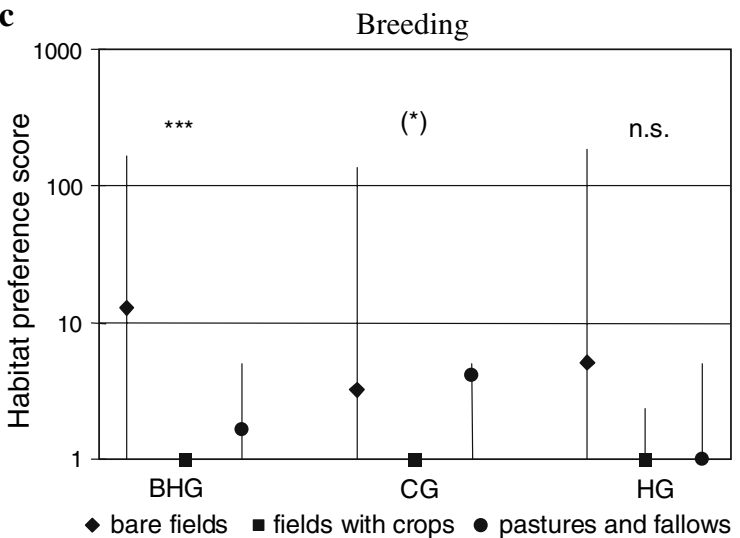

d

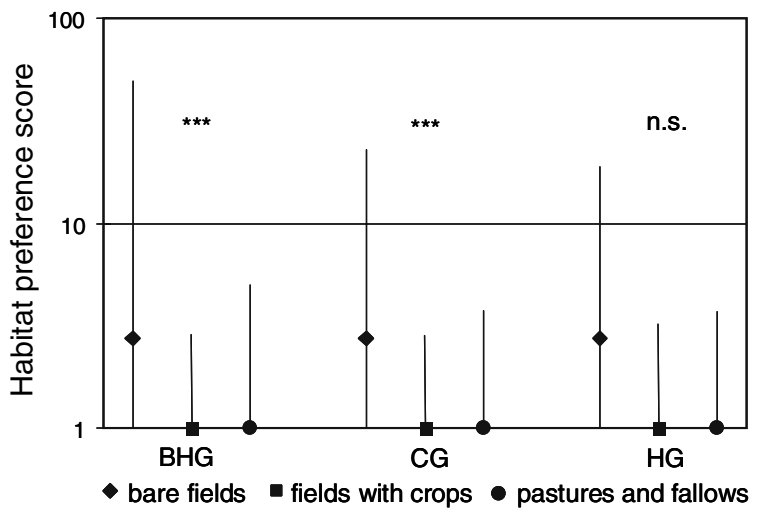

three habitat classes within each gull species. $(*) P \leq 0.1$, $* P \leq 0.05, * * P \leq 0.005, * * * P \leq 0.001$, n.s., not significant 
test: $\left.T^{+}=87 ; N=12 ; P<0.005\right)$. During breeding, there was an insignificant tendency for BHGs occurring more frequently on bare fields compared to CGs and HGs (Fig. 3c). During both migration periods no significant differences in habitat use between the species were detected (Fig. 3b, d).

Mean gull densities on different habitat types

BHGs showed the highest total densities in the larger study area except in winter, when CGs dominated. HGs revealed total densities of $<5$ individuals $\mathrm{km}^{-2}$ during every season. BHG reached highest densities on ploughed, drilled and harvested fields, while CG were mainly found on pasture except during both periods of migration. Numbers of HG were highest either on pasture or ploughed fields. Generally, vegetables (except during breeding), colza and fallow fields did not show high densities of any species (Table 3).

Gull abundance in relation to abiotic factors

Each of the abiotic parameters influenced gull abundance significantly, except wetness of the soil (Table 4). In general, presence of active tractors had the strongest positive effect on gull numbers (no test for consistence necessary; see arrows in Table 4). Time of day was negatively correlated with gull

Table 3 Mean densities (as individuals $\mathrm{km}^{-2}$ ) of gull species on different habitat types during the four seasons recorded during 12 counts within the larger study area (total area of numbers (except BHG during breeding; consistence tested by $t$-test of Spearman's rank correlation coefficients: mean $r_{\mathrm{S}}=-0.29 ; t=-3.42$; df $=6$; $P<0.05)$. Wind force and tide did not show consistent effects (mean $r_{\mathrm{S}}=-0.004 ; t=0.02$; df $=6$; $P=0.99$ and mean $r_{\mathrm{S}}=-0.18 ; t=-1.05 ; \mathrm{df}=6$; $P=0.33$, respectively). Although wetness of the soil itself had no significant effect, numbers increased most drastically during wet conditions when tractors were present, indicating a combined effect of both parameters.

\section{Behaviour of gulls}

Behaviour of the three gull species differed significantly $\left(\chi^{2}=2833.5\right.$; df $=4 ; P<0.001$; Fig. 4a). All species but CG spent more than $40 \%$ of their time resting, while the latter was mostly found foraging in habitats undisturbed by tractors. Of all species BHG foraged most intensively behind tractors (23\%). Individuals foraging in habitats undisturbed by tractors most commonly walked over the ground while searching, but a small proportion of CGs and BHGs $(<5 \%)$ foraged flying while continuously dipping to the ground. A small number of naturally foraging BHGs was recorded in aerial pursuit for insects (4\%), whereas no other species foraged that way.

Twenty-six of 124 tractors recorded were not attended by gulls (21\%). About 106 tractors (85\%) were preparing the soil by ploughing or drilling.

$28.3 \mathrm{~km}^{2}$; see "Materials and methods" for details; - = habitat type not available; for species abbreviations see Table 2)

\begin{tabular}{|c|c|c|c|c|c|c|c|c|c|c|c|c|}
\hline & \multicolumn{3}{|c|}{ Winter } & \multicolumn{3}{|c|}{ Spring migration } & \multicolumn{3}{|c|}{ Breeding } & \multicolumn{3}{|c|}{ Autumn migration } \\
\hline & BHG & $\mathrm{CG}$ & $\mathrm{HG}$ & BHG & $\mathrm{CG}$ & $\mathrm{HG}$ & $\mathrm{BHG}$ & $\mathrm{CG}$ & $\mathrm{HG}$ & BHG & $\mathrm{CG}$ & $\mathrm{HG}$ \\
\hline Drilled & 0 & 0.2 & 0 & 29.7 & 1.3 & 0 & 393.5 & 15.1 & 17.4 & 175.7 & 74.0 & 4.0 \\
\hline Ploughed & 10.3 & 31.3 & 0.3 & 255.1 & 21.7 & 95.7 & 61.5 & 6.4 & 28.9 & 474.2 & 200.6 & 7.0 \\
\hline Harvested crops & 1.7 & 3.3 & 0.2 & - & - & - & 305.8 & 0 & 0 & 684.4 & 3.9 & 0 \\
\hline Vegetables & 0 & 0 & 0 & 0 & 0 & 0 & 50.0 & 9.9 & 20.5 & 13.7 & 2.9 & 0 \\
\hline Colza & 0 & 0.3 & 0 & 0 & 0 & 0 & 0 & 0 & 0 & 0 & 0.1 & 0 \\
\hline Stubble & 1.1 & 2.5 & 0.5 & 0 & 0 & 0 & 2.1 & 0 & 3.2 & 31.4 & 12.2 & 6.3 \\
\hline Winter wheat & 0.2 & 3.8 & 2.6 & 30.0 & 4.7 & 0.4 & 0.7 & 0 & 0 & 6.0 & 16.7 & 0.1 \\
\hline Fallow & 0 & 0 & 0 & 23.3 & 0 & 0 & 0 & 0 & 0 & 4.4 & 1.5 & 0 \\
\hline Pasture & 8.9 & 44.9 & 7.9 & 36.9 & 8.1 & 3.5 & 15.3 & 15.1 & 15.5 & 32.2 & 44.3 & 7.7 \\
\hline Total density in study area & 3.1 & 14.3 & 2.8 & 33.4 & 4.7 & 3.6 & 15.4 & 3.7 & 4.7 & 54.9 & 32.5 & 2.7 \\
\hline
\end{tabular}




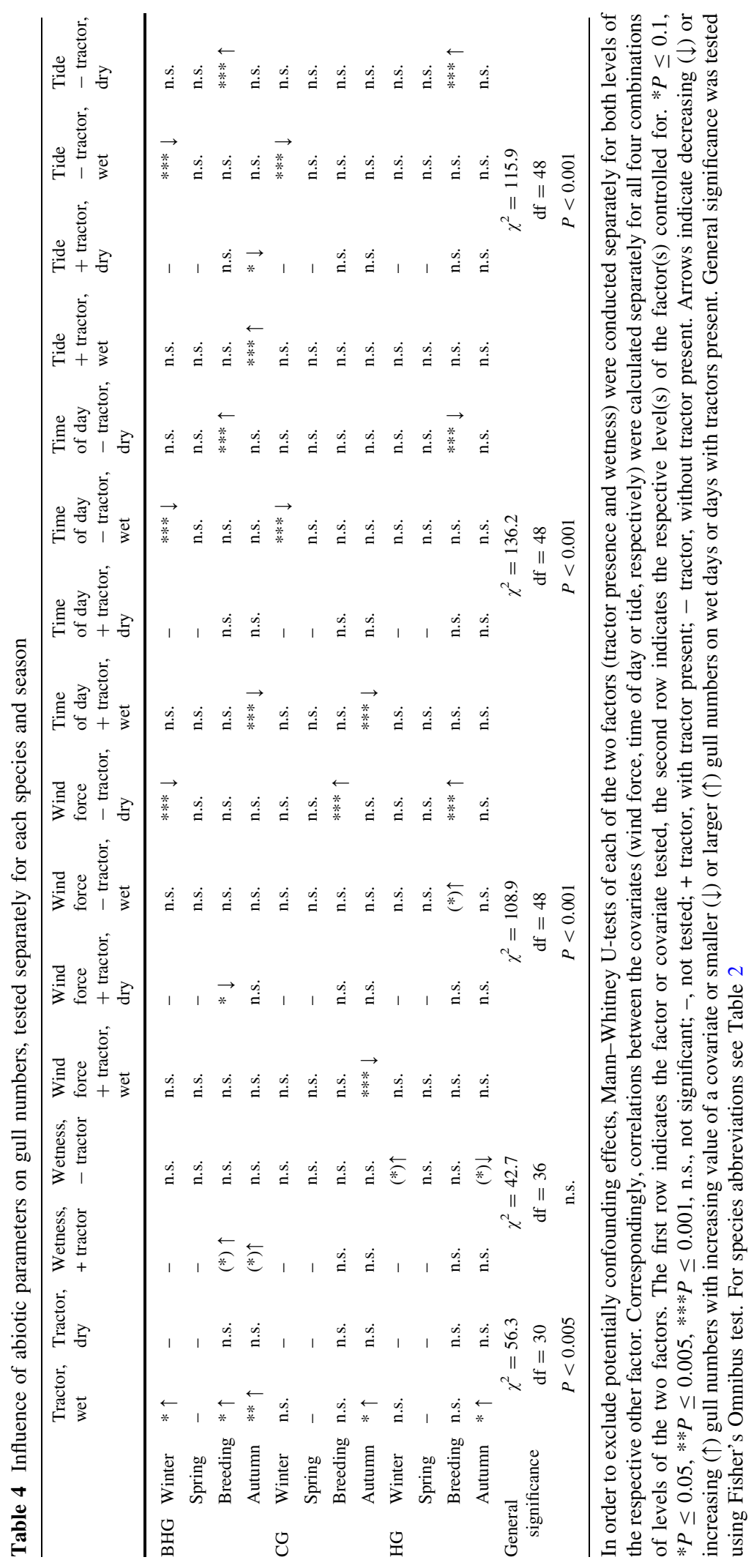



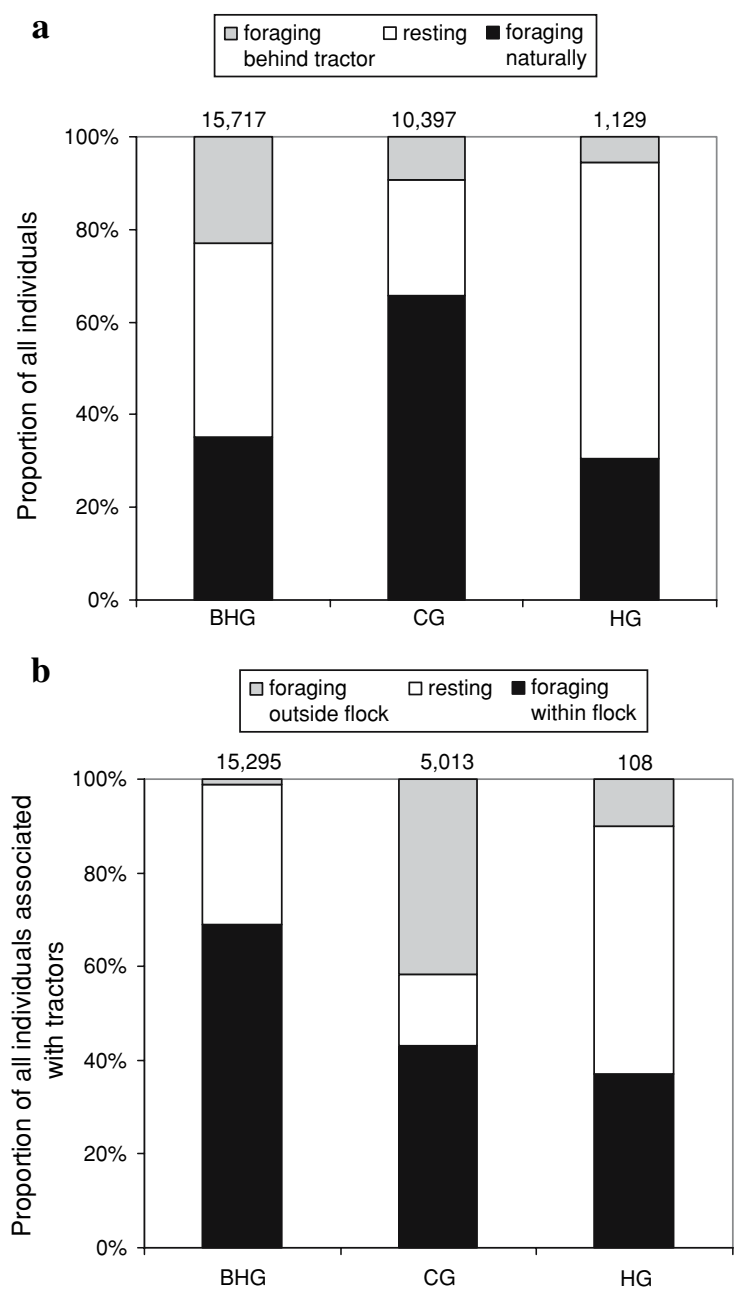

Fig. 4 (a) Behaviour of all gulls within the transect area during 115 counts expressed as proportions on three behaviour categories (foraging naturally = foraging in habitats undisturbed by tractors). (b) Behaviour of gulls associated with 124 tractors within the larger study area expressed as proportion on three behaviour categories. Numbers above the columns depict the numbers of gulls included

These generally attracted the largest flocks of gulls (mean number of all individuals: 182). The other 18 tractors $(15 \%)$ were harvesting, mowing, or deploying dung and did not attract as many birds (mean number of all individuals: 63). Difference in flock size behind the two types of tractors were significant (Mann-Whitney $U$-test: $U=570 ; P<0.01$ ). Species composition behind tractors was clearly dominated by BHGs (78.8\% of all gulls associated with tractors), followed by CGs $(20.6 \%)$ and HGs $(0.6 \%)$.
Table 5 Proportions of gulls associated with tractors out of the total of all gulls recorded during each season and the total numbers of gulls counted (in brackets)

\begin{tabular}{llll}
\hline & BHG & \multicolumn{1}{l}{ CG } & HG \\
\hline Winter & $25.9 \%(641)$ & $5.9 \%(3,536)$ & $5.6 \%(425)$ \\
$\begin{array}{l}\text { Spring } \\
\quad \text { migration }\end{array}$ & $33.2 \%(4,432)$ & $11.2 \%(1,712)$ & $8.2 \%(428)$ \\
$\begin{array}{l}\text { Breeding } \\
\text { Autumn } \\
\quad \text { migration }\end{array}$ & $31.2 \%(2,508)$ & $18.5 \%(54)$ & $11.4 \%(105)$ \\
$\begin{array}{c}\text { Overall } \\
\text { average }\end{array}$ & $32.4 \%(17,093)$ & $16 \%(10,256)$ & $6.8 \%(1,067)$ \\
\hline
\end{tabular}

For species abbreviations see Table 2

Proportions of gulls associated with tractors on the total during each season differed significantly between the three species $\left(\chi^{2}=653.2 ; \mathrm{df}=6\right.$; $P<0.001)$. BHG and $\mathrm{CG}$ reached highest values during autumn migration. Throughout the year BHG revealed the highest proportions (Table 5). The behaviour of gulls behind tractors differed significantly between species $\left(\chi^{2}=6317.7 ; \mathrm{df}=4 ; P<\right.$ 0.001): most BHGs foraged in dense flocks in the vicinity of the tractor, whereas CGs showed a higher proportion of individuals foraging outside of the flock and most HGs were found resting (Fig. 4b).

\section{Discussion}

Temporal and spatial habitat utilization

Our findings suggest an important role of terrestrial (nearshore) agricultural habitats for the two smaller species of gull, whereas the two larger species occur in lower numbers. These findings fit well previous analyses of the basic ecology of the four gull species: The LBBG at the eastern North Sea coast is mainly an offshore species that flies long distances in order to feed at sea (e.g. Verbeek 1977; Camphuysen 1995; Kubetzki and Garthe 2003; Schwemmer and Garthe 2005). HGs have been described to mainly use intertidal habitats for foraging (Spaans 1971; Verbeek 1977; Kubetzki and Garthe 2003), though, in our study, the adjacent terrestrial mainland supported moderate numbers during certain periods of the year (Fig. 2; Table 2). HGs use the farmland habitats only partly for foraging, as a high proportion 
of individuals have been found resting (Fig. 4a). Thus, the most important niche segregation patterns between the two small and large gull species are based on a broader spatial scale, and the structure of the habitat mosaic of the farmland will have minor significance for the two larger species (probably least for LBBGs). As BHG and CG are the most important species in terrestrial habitats (Fig. 2; Table 2; see also Vernon 1970a) and are much more affected by small scale differences of the habitat mosaic, they will be emphasised in the subsequent discussion.

Although none of the species investigated showed a distinct preference for a single habitat category, the most obvious and basic difference existed between CGs and BHGs: the former species particularly preferred pastures, whereas the latter was frequently associated with recently cultivated fields. But, our findings also show that this general pattern was not consistent throughout the year. We found significantly higher preference values for bare fields in BHG compared to CG during winter and a trend for the same relationship during breeding, whereas no such significant difference was found during both migration periods. Reasons for these patterns can be explained by taking into account the influence of agricultural practices: whereas the availability of the ploughed, harvested and drilled habitats changed dramatically, the availability of fallow and pasture stayed more or less constant during the year (Table 1). It is important to investigate the seasonal differences in habitat utilization in more detail.

\section{Migration}

Recently cultivated fields provide important food sources for gulls several days after soil preparation (Cuendet 1983). Farming activity is intense during both migration periods (particularly autumn), leading to high numbers of such food sources. Consequently, there was a weak preference for fields without recent farming activities in all species, including CG. Peak numbers of gulls in the mainland during both periods of migration (Fig. 2) are confirmed by other studies (Platteeuw 1987; Pedersen et al 2000). The rich food supply during migration seems to support high total individual numbers.

\section{Breeding}

In contrast to migration periods, the total area of suitable foraging habitats during the breeding season can be considered as particularly low, because (1) vegetation on most fields is high and thus not suitable for foraging (Morris 2000; Butler and Gillings 2004; Devereux et al. 2006) and (2) the intensity of soil preparation before harvesting is low. Few gulls are thus present at this time, except BHGs on bare fields. CG numbers are low at this time due to the comparatively small breeding population on the German North Sea coast (Garthe et al. 2000; Kubetzki 2001).

\section{Winter}

Although during winter there is still a moderately high availability of fields with open soils (Table 1), it is the time with lowest farming activities. Gulls are forced to obtain their food by natural foraging. BHGs seem to be most dependent on food resources produced by human activities as indicated by the preference of bare fields and significant correlations to presence of tractors. Such food resources are scarce during winter, and this might explain the low numbers of this species in comparison to CGs that mainly use pastures.

The patterns of temporal and spatial habitat utilization of the four gull species are thus highly variable. This is certainly caused by the rapidly changing food availability related with anthropogenic activities as well as by the general flocking behaviour of gulls (see below). However, despite of this variability, the general preferences for certain habitats of $\mathrm{BH}$ and $\mathrm{CG}$ are clear.

\section{Dietary and behavioural habitat partitioning}

As revealed by dietary analysis of CGs, earthworms can make up to $90 \%$ of gull food (Vernon 1970b, 1972; Kubetzki 2001). Earthworms show much higher biomass values under pastures compared to any type of arable land, as a result of a higher content of organic matter (Cuendet 1983; Edwards 1983). Furthermore, the age of the pasture is positively correlated with earthworm densities (Eijsackers 
1983). Also, abundance of arthropods in grazed pastures (e.g. dung-dwelling specialists) was found to be higher compared to mowed sites (Vickery et al 2001; Barnett et al 2004). About $73 \%$ of the pastures in our study area is permanent grassland, grazed by animals instead of being cut for hay production or silage. Consequently, organic matter content and thus earthworm and arthropod abundance can be expected to be high. Biomass of earthworms under pasture reaches highest values during late autumn and early winter (Watkin and Wheeler 1966). This should offer good feeding opportunities for CGs and is presumably an important reason for their high numbers on pastures during (early) winter. As BHGs are more dependent on food related with farming activities, they might be at a disadvantage when such ephemeral food resources diminish in winter.

Despite temporal and spatial habitat partitioning apparently existing between CG and BHG, we found a high variance in habitat preference and frequent feeding in mixed flocks. This might be due to the effect of local enhancement: the exploitation of food resources can be increased by high numbers of individuals (also of different species) joining in foraging actions (e.g. Waite 1981). Individual food intake rate can be increased by foraging within larger flocks, as high individual numbers indicate high food availability. However, CGs were less frequently found in dense flocks behind tractors compared to BHGs and foraged more frequently outside such flocks and also spent much more time foraging on sites undisturbed by tractors (Fig. 4). Additionally, BHGs behind tractors kleptoparasitize CGs and conspecifics frequently (our own observations), a behaviour that typically occurs when the prey is locally superabundant (Brockmann and Barnard 1979), which is the case behind tractors but not in naturally foraging individuals. BHGs are most successful exploiting ephemeral patches with superabundant food caused by soil preparation. In contrast, the earthworms and other arthropods found in pastures are not available in such quantities. Thus, CGs, that use pastures most intensively, spent more time for foraging instead of resting (Fig. 4a).

In conclusion, differences in the exploitation of farming practices can be considered as the most important feature in niche segregation between the two small gull species. Hunt and Hunt (1973) showed that small gull species tend to utilize habitats which provide small food items that can be handled more easily. As tractors stir up insects and other comparatively small prey, this might explain why HGs were rarely found foraging behind farming tractors and their abundance was not significantly correlated with the presence of tractors (Table 3).

\section{Gull abundance in relation to abiotic parameters}

The availability of natural food resources and thus gull abundance is supposed to correlate with meteorological parameters (e.g. Steele 1989; Honza 1993). Earthworms are most available during wet conditions as well as in the early morning hours (Kruuk 1978; Sibly and McCleery 1983), and in our study, we detected significantly higher numbers of all gulls in the morning hours compared to the rest of the day. Wetness, however, did not significantly influence gull abundance in general (although we found indications for higher gull numbers during wet conditions). Presumably, wet soil alone did not suffice to increase the availability of soil invertebrates, but in connection with soil preparation it seems to lead to higher prey availability. As earthworms migrate towards the upper soil layers during wet conditions (e.g. Satchell 1967), the proportion of the total earthworm population that becomes available during soil preparation is likely to be much higher compared to dry conditions, when many individuals are located below the depth of the ploughshare.

Wind force is able to influence prey availability (especially earthworms) only indirectly by changing air humidity (e.g. Kruuk 1978). We found that wind force strongly affected gull abundance (though very inconsistently; Table 4). During severe weather (Vernon and Walsh 1966; our own observations) a high proportion of individuals may be forced to abandon the submerged high tide roost sites in saltmarshes and tidal flats and shelter in flocks inland. This aggregated dispersal would lead to low individual numbers if flocks built up outside our study area or it would lead to high values if flocks were located within the study area. Thus, though high winds may increase overall numbers, we were unable to detect this because our study area was too small. As high tide roosts may also be located inland, inconsistent relationships would also be expected 
with the stage of the tide. The same holds true for the influence of time of day, as gulls would congregate towards evening prior to roosting. These effects additionally enhance the variability of the data.

The presence of tractors influenced gull numbers most explicitly and possibly superimposed effects of other parameters. We tried to account for that by splitting the data set into observation days with and without tractors. However, the analysis of the other abiotic parameters may still be biased, if tractors were present outside but in the vicinity of the study area. We believe that the rather high numbers of observation days might account for such a bias.

The analysis of abiotic parameters does not suggest any substantial differences between the species that would indicate niche segregation patterns, except presence of tractors that clearly seemed to be most favourable for BHGs.

\section{Conclusions}

Differences in area utilization in the coastal mainland between BHGs and CGs and partly also the two larger species were explicitly connected to anthropogenic activities which BHGs seemed able to exploit most effectively. CGs were found to depend on less disturbed sites in winter and summer. The availability of a mosaic of different habitat types supports niche segregation between the species.

However, during the last 30 years profound changes in agricultural practices have taken place throughout northern Europe (Chamberlain et al. 2000; Buckwell and Armstrong-Brown 2004). Such long-term habitat modifications can significantly influence habitat utilization, species diversity and population sizes as already shown for various bird species (Duncan et al 1999; Chamberlain et al. 2000; Atkinson et al. 2002). For gulls, the most crucial changes are in the overall and continuous decline of the total area of pastures for the benefit of tillage as well as the intensification of grassland management, i.e. mowing and silage making (Chamberlain et al. 2000; Kubetzki 2001; Vickery et al. 2001; Barnett et al. 2004). This development is certainly most favourable for BHG (see also Barnett et al. 2004), while it might cause long-term severe effects for CG which are much more dependent on carefully managed pastures at least during winter.
Agricultural intensification and loss of pastures (Garthe et al. 2000) might become more critical for CGs in the near future. However, at present the four gull species occupy distinct ecological niches at the North Sea coast, as the two large species show low numbers in the coastal mainland, while the two smaller ones reveal temporal and spatial habitat partitioning patterns as well as important differences in behaviour and utilization of food resources.

Acknowledgements We thank the "Vermessungs- und Katasterverwaltung Schleswig-Holstein" (Meldorf) for providing digital map data and allowing publication of the transect map. Parts of the work are related to the project MINOSplus funded by the Federal Environmental Ministry. H. Dries and S. Weiel assisted in data collection. We are grateful to V. Dierschke for commenting on an earlier version of this manuscript. N. Burton, R. Pierotti and one anonymous reviewer made very valuable suggestions to improve the manuscript.

\section{References}

Atkinson PW, Fuller RJ, Vickery JA (2002) Large-scale patterns of summer and winter bird distributions in relation to farmland type in England and Wales. Ecography 25: 466-480

Barnett PR, Whittingham MJ, Bradbury RB, Wilson JD (2004) Use of unimproved and improved lowland grassland by wintering birds in the UK. Agric Ecosyst Environ 102: 49-60

Begon M, Townsend CR, Harper JL (2006) Ecology: from individuals to ecosystems, 4th edn. Blackwell, Oxford

Brockmann HJ, Barnard JC (1979) Kleptoparasitism in birds. Anim Behav 27:487-514

Buckwell A, Armstrong-Brown S (2004) Changes in farming and future prospects - technology and policy. Ibis 146: 14-21

Butler SJ, Gillings S (2004) Quantifying the effects of habitat structure on prey detectability and accessibility to farmland birds. Ibis 146:123-130

Camphuysen CJ (1995) Herring gull Larus argentatus and lesser black-backed gull L. fuscus feeding at fishing vessels in the breeding season: competitive scavenging versus effective flying. Ardea 83:365-380

Chamberlain DE, Fuller RJ, Bunce RGH, Duckworth JC, Shrubb M (2000) Changes in the abundance of farmland birds in relation to the timing of agricultural intensification in England and Wales. J Appl Ecol 37:771-788

Cuendet G (1983) Predation on earthworms by the blackheaded gull Larus ridibundus. In: Satchell JE (ed) Earthworm ecology - from Darwin to vermiculture. Chapman and Hall, London, pp 415-424

Dernedde T (1994) Foraging overlap of three gull species (Larus spp.) on tidal flats in the Wadden Sea. Ophelia Suppl 6:225-238 
Devereux CL, Whittingham MJ, Krebs JR, Juricic F, Vickery JA (2006) What attracts birds to newly mown pasture? Decoupling the action of mowing from the provision of short swards. Ibis 148:302-306

Duncan P, Hewison AJM, Houte S, Rosoux R, Tournebize T, Dubs F, Burel F, Bretagnolle V (1999) Long-term changes in agricultural practices and wildfowling in an internationally important wetland, and their effects on the guild of wintering ducks. J Appl Ecol 36:11-23

Edwards CA (1983) Earthworm ecology in cultivated soils. In: Satchell JE (ed) Earthworm ecology - from Darwin to vermiculture. Chapman and Hall, London, pp 123-137

Eijsackers HJP (1983) Development of earthworm populations in abandoned arable fields under grazing management. In: Satchell JE (ed) Earthworm ecology - from Darwin to vermiculture. Chapman and Hall, London, pp 241-246

Garthe S, Flore BO, Hälterlein B, Hüppop O, Kubetzki U, Südbeck P (2000) Brutbestandsentwicklung der Möwen Laridae an der deutschen Nordseeküste in der zweiten Hälfte des 20. Jahrhunderts Vogelwelt 121:1-13

Haccou P, Meelis E (1994) Statistical analyses of behavioural data. Oxford University Press

Honza M (1993) Factors influencing the foraging patterns of the black-headed gull Larus ridibundus from breeding colonies. Folia Zool 42:243-249

Horton N, Brough T, Rochard JBA (1983) The importance of refuse tips to gulls wintering in an inland area of southeast England. J Appl Ecol 20:751-765

Hunt GL, Hunt MW (1973) Habitat partitioning by foraging gulls in Maine and northwestern Europe. Auk 90:827-839

Kruuk H (1978) Foraging and spatial organisation of the European badger Meles meles. Behav Ecol Sociobiol 4:75-89

Kubetzki U (2001) Zum Bestandsrückgang der Sturmmöwe Larus canus an der schleswig-holsteinischen Ostseeküste Ausmaß, Ursachen und Schutzkonzepte. Corax 18: 301-323

Kubetzki U, Garthe S (2003) Distribution, diet and habitat selection by four sympatrical gull species in the southeastern North Sea. Mar Biol 143:199-207

Manly BFJ (1997) Randomization, bootstrap and Monte Carlo methods in biology. Chapman \& Hall, New York

Morris MG (2000) The effects of structure and its dynamics on the ecology and conservation of arthropods in British grasslands. Biol Conserv 95:129-142

Mundry R, Fischer J (1998) Use of statistical programs for nonparametric tests of small samples often leads to incorrect P-values: examples from animal behaviour. Anim Behav 56:256-259
Pedersen KT, Fritze EB, Kharitonov SP (2000) Migration patterns of common gulls Larus canus ringed in the nonbreeding season in Copenhagen and the surrounding area. Ringing Migr 20:97-106

Platteeuw M (1987) Trekbewegingen van Kokmeeuwen Larus ridibundus langs de Noordzeekust: oorzaken en achtergronden. Sula 1:29-37

Satchell JE (1967) Lumbricidae. In: Burges A, Raw F (eds) Soil biology. Academic Press, London, pp 259-322

Schwemmer P, Garthe S (2005) At-sea distribution and behaviour of a surface feeding seabird, the lesser blackbacked gull Larus fuscus, and its association with different prey. Mar Ecol Prog Ser 285:245-258

Sibly RM, McCleery RH (1983) The distribution between feeding sites of herring gulls breeding at Walney Island, U.K. J Anim Ecol 52:51-68

Siegel S, Castellan NJ (1988) Nonparametric statistics for the behavioral sciences, 2nd edn. McGraw-Hill, New York

Spaans AL (1971) On the feeding ecology of the herring gull Larus argentatus Pont. in the northern part of the Netherlands. Ardea 59:73-188

Steele WE (1989) Factors influencing inland foraging by gulls. Ostrich 60:45-47

Verbeek NAM (1977) Comparative feeding ecology of Herring gulls Larus argentatus and Lesser black-backed gulls Larus fuscus. Ardea 65:25-42

Vernon JDR (1970a) Feeding habitats and food of the blackheaded and common gulls. Part 1 - feeding habitats. Bird Study 17:287-296

Vernon JDR (1970b) Food of the common gull on grassland in autumn and winter. Bird Study 17:36-38

Vernon JDR (1972) Feeding habitats and food of the blackheaded and common gulls. Part 2 - food. Bird Study 19:173-186

Vernon JDR, Walsh TP (1966) The common gull in the Severn Estuary in relation to feeding areas, roost sites and behaviour. Proc Bristol Nat Soc 31:173-184

Vickery JA, Tallowin JR, Feber RE, Asteraki EJ, Atkinson PW, Fuller RJ, Brown VK (2001) The management of lowland neutral grasslands in Britain: effects of agricultural practices on birds and their food resources. J Appl Ecol 38:647-664

Waite RK (1981) Local enhancement for food finding by rooks Corvus frugilegus foraging on grassland. Z Tierpsycho 57:15-36

Watkin BR, Wheeler JL (1966) Some factors affecting earthworm populations under pasture. J Brit Grass Soc 21: $14-20$ 